\title{
Hospital community benefits and the effect of Schedule H: A difference-in-difference approach
}

\author{
Helen Schneider ${ }^{1^{*}}$, Hilal Yilmaz ${ }^{2}$ \\ ${ }^{1}$ Economics Department, The University of Texas at Austin, Austin, USA; \\ ${ }^{*}$ Corresponding Author: h.schneider@eco.utexas.edu \\ ${ }^{2}$ Economics Department, St. Edward's University, Austin, USA
}

Received 7 August 2013; revised 7 September 2013; accepted 23 September 2013

Copyright (C) 2013 Helen Schneider, Hilal Yilmaz. This is an open access article distributed under the Creative Commons Attribution License, which permits unrestricted use, distribution, and reproduction in any medium, provided the original work is properly cited.

\section{ABSTRACT}

Since 1969 private, nonprofit hospitals have qualified for tax exemption as charitable institutions and in exchange for the preferential tax treatment were required to provide community benefits. However, in the absence of mandatory reporting of community benefits at the federal level and in the absence of a clear definition of community benefits, the previous literature provides but ambiguous evidence regarding hospitals' supply of community benefits. Responding to policymakers' concerns, the Internal Revenue Service (IRS) mandates all private, nonprofit hospitals to report charity care at cost as well as unreimbursed Medicaid costs starting with the tax year 2008. Using data from hospitals in California before and after tax year 2008 (2009 filing), this study examines whether changes in the IRS 990 Schedule $H$ had a significant effect on the supply of community benefits by nonprofit hospitals relative to for-profit hospitals. Empirical results suggest that nonprofit hospitals do not supply more community benefits relative to for-profit hospitals for both definitions of community benefits reported in Schedule $\mathbf{H}$. Although the supply of community benefits increased for all hospitals after 2008, the increase was not higher for nonprofits. Moreover, nonprofits supplied significantly less community benefits according to some definitions. Thus, minimum charity care standard is justified.

Keywords: Hospitals; Community Benefits; Uncompensated Care

\section{INTRODUCTION}

There has been much debate over the extent to which nonprofit hospitals deserve the tax exempt status afforded to them under the state and federal laws. The debate over nonprofit hospitals' tax exempt status is also fueled by a perception that nonprofit hospitals replaced their community orientation with profitability, and they did it by increasingly aggressive billing and collection practices and inadequate supply of charity care to the uninsured and medically indigent patients.

Although nonprofit hospitals are expected to provide community benefits in exchange for their tax exemption, prior to tax year 2008 the Internal Revenue Service (IRS) Form 990 did not request hospitals to quantify the value of the community benefits they provided. Moreover, Kane (2006) reports that less than $1 \%$ of hospital 990 forms were subject to annual audit [1]. Prior to 2008, the US Government Accountability Office (2008) reports two changes in the federal community benefits standard over time [2]. First, the original IRS revenue ruling in 1956 defined free health services to the poor as the requirement necessary to qualify for the nonprofit status. However, this pure charity care standard was later replaced with community benefits standard that gave hospitals more flexibility in defining what they deem to be community benefits.

Finally, responding to policymakers' concerns in December of 2007, the IRS released the new Form 990 for tax year 2008 (to be filed in 2009) where all nonprofit hospitals are required to quantify community benefits as defined by the IRS.

Until 2008 the lack of mandatory requirement at the federal level, and with only a few states ever collecting hospital community care contributions, there has been very little accountability in place. Salinsky (2009) identifies 13 states that mandate community benefits reporting 
(California, Connecticut, Georgia, Idaho, Illinois, Indiana, Maryland, Minnesota, New Hampshire, New York, Rhode Island, Texas and Washington), and of these thirteen states three had never defined community benefits (Connecticut, Georgia, and New York) [3]. In addition, for the states that do define community benefits, the definition varies across states. For example, California's Charity Care and Discount Payment Law of 2006 requires all general acute-care (and some specialty hospitals) to report charity care, payment discounts and government-sponsored health coverage programs. While California allows the inclusion of Medicare and Medicaid shortfalls, other states defined community benefits more narrowly excluding such shortfalls (Minnesota, New Hampshire, Rhode Island, and Washington). In addition, many states include bad debt into their definition while California excludes it. The lack of uniform definition and clarity complicated comparing the community benefits across hospitals and across the states. It is also important to note that neither state laws nor the revised Schedule $\mathrm{H}$ impose any penalties on hospitals that fail to meet the reporting requirement.

We believe that current policy change can affect nonprofit hospital supply of community benefits for several reasons. First, as Gray and Schlesinger (2009) point out, due to the new mandatory data collection at the federal level hospitals may work harder to capture the pertinent data and may be forced to improve reporting of such benefits [4]. Thus, we may see an increase in community benefits due to better data collection rather than greater charity care supply. Second, nonprofit hospitals may fear the loss of their tax exempt status if they fail to prove their community orientation. In this case we may realistically expect to see more indigent patients being served by nonprofit hospitals. This effect may be especially strong for the community benefits specifically identified in Schedule H and for the "outlier" hospitals that provide significantly less community care than their peer institutions. Finally, Schedule H reporting may pressure some hospitals to relinquish their nonprofit status thus increasing community benefits being reported by the remaining nonprofit hospitals.

To date, previous literature of the effect of mandatory state reporting requirements and of the effect of the new Schedule $\mathrm{H}$ changes is very limited. In his comprehensive literature review of the effect of state reporting requirements on community benefits, Hellinger (2009) finds that volume of uncompensated care (where uncompensated care is defined as charity care plus bad debt) increased for the states that stipulated minimum requirements for the tax exempt hospitals to meet [5]. Similarly, Sutton and Stenslend (2004) looked at the data between 1996 and 1998 and found that hospitals in Texas provided more than three times the charity care compared with the hospitals in California [6]. This result is attributed to 1995 Texas health and safety code rule 311.0466 that mandates data on community benefits and requires charity care equal to at least $5 \%$ of net patient revenues. Gray and Schlesinger (2009) find that mandated community benefit requirement in Maryland increased the supply of community benefits in the state but the increase was not uniform across hospitals [4]. Hospitals with the lowest community benefit expenditures saw the largest increase while hospitals with the highest community benefits expenditures saw only a minor increase. CBO (2006) study examined the volume of community benefits provided by nonprofit hospitals in California, Florida, Georgia, Indiana, and Texas and found that only in states that set minimum standard (Texas and Indiana) the differences in community benefits between nonprofit hospitals and for-profit hospitals are large [7]. It is important to note that revised Form 990 of Schedule H only requires data on hospitals' community benefits but does not set a minimum standard that nonprofit hospitals have to meet to maintain their tax exemption.

Without a shared definition of community benefits, it is indeed difficult to determine whether or not the nonprofit hospitals supply more community benefits than for-profit hospitals. Previous studies that concentrate on hospital supply of uncompensated care do not yield a consensus about nonprofit hospitals' contribution relative to their for-profit counterparts. Thus, Morrisey et al. (1996) found that in California close to $20 \%$ of all nonprofit hospitals do not provide more uncompensated care than the for-profit hospitals [8]. Norton and Staiger (1994) found that nonprofit hospitals provide a similar amount of uncompensated care but they tend to locate in areas with higher demand for charity care [9]. Studies that looked at a broader definition of community benefits in order to estimate whether nonprofit hospitals warrant their tax exemption show that the answer largely depends on the definition of community benefits and inclusion of Medicare and Medicaid shortfalls [10,11]. Bazzoli et al. (2010) is the first study that looked at the new IRS Schedule $\mathrm{H}$ definition of community benefits and found that in 2005, prior to mandated Schedule H, both California and Florida hospitals did not provide community benefits in excess of for-profit hospitals [11]. Nonprofit hospitals only met the benchmark when both bad debt and Medicare shortfalls were included. Since the study only looked at pre-Schedule $\mathrm{H}$ community benefits, it is not clear whether or not the mandated reporting would tangibly change these results.

Our study contributes to the previous literature on several fronts. First, we quantify community benefits for all California general acute care hospitals before and after the mandated Form 990 Schedule H change. Since IRS ruling affects the nonprofit hospitals only, we use 
difference-in-difference analysis to identify the changes in community benefits induced by the policy change. Then, we look separately at the changes in charity care and MediCal (California Medicaid program) shortfalls that have been identified by the IRS ruling as community benefits and at bad debt and Medicare shortfalls that hospitals report to the IRS but that are not considered community benefits per se. Finally, this study will illuminate the effect of the mandated community benefits reporting on hospital supply of community benefits that hospitals are required to quantify and publicly disclose.

\section{DEFINING AND MEASURING COMMUNITY BENEFITS}

Part I of Schedule H collects quantitative information on the costs that hospitals incur in providing charity care and "certain other community benefits". Part I includes free or discounted health services provided to persons who meet the hospital's criteria for financial assistance and unreimbursed costs of providing care to recipients of means tested government programs (such as Medicaid and SCHIP). In addition, in a separate part the schedule asks hospitals to report unreimbursed costs of Medicare and bad debt and then provide a written rationale for why some or all of these costs should be considered community benefits. GAO (2008) found that in the state of California alone, Medicare shortfalls and bad debt together account for $70 \%$ of uncompensated care costsand between two-thirds to three quarters of uncompensated care costs nationally [2]. Thus, hospitals will be hard pressed to justify the inclusion, at least partially, of these costs as community benefits.

Table 1 summarizes and defines community benefits.

Hospitals are also able to report education, research, and charitable donations as community benefits. Part II collects community building activities that strengthen a community infrastructure while having only an indirect effect on the health of the population. This study will not investigate these latter costs since they represent only a minor part of unreimbursed hospital expenditures [2].

In this report we quantify all community benefits reported in Table 1 for a sample of general acute care hos- pitals in California. Note that all community benefits were adjusted by the hospital specific cost-to-charge ratios. Gifts and subsidies were then netted out, as required by Schedule $\mathrm{H}$.

\section{METHODS}

California is one of thirteen states that mandated disclosure of charity care contributions at the state level before implementation of Schedule H. However, we believe that nonprofit hospitals in states like California do make for a suitable experimental group. First, in California charity care data was not reported to the tax authorities but rather to California's Office of Statewide Health Planning and Development (OSHPD) alongside other accounting variables. OSHPD never used the data to hold hospitals accountable for providing potentially low supply of community benefits. More importantly, the data was not reported at cost. Hence, to translate charges to cost, an outside information on hospital-specific cost-tocharge ratio has to be applied. In addition, charitable contributions reported to OSHPD are never adjusted for subsidies. Not surprisingly, once adjusted to reflect costs and subsidies, some hospitals in California actually reported negative amounts of pure charity care before Schedule $\mathrm{H}$ was phased in (i.e. some hospitals received subsidies in excess of their contributions). These negative charity care numbers disappear after tax year 2008 . Finally, as discussed above, California's definition of community benefits deviates from that defined by Schedule $\mathrm{H}$.

\subsection{Empirical Model}

In our analysis we adopt the difference-in-difference approach to check whether nonprofit hospitals significantly increased their supply of community benefits relative to for-profit hospitals after the changes in the 2008 IRS 990 Schedule H. To determine this effect we introduce After 08 dichotomous variable in our regression, which equals 0 if the data is from 2006-2007 period (before the policy change) and 1 if the data is from 20092010 period (after the policy change). Interaction variable

Table 1. Community benefits considered in the new IRS Form 990 Schedule H.

\begin{tabular}{|c|c|}
\hline Community benefit & Definition \\
\hline Pure charity care & $\begin{array}{l}\text { Part of care for which payment is not expected and patients are not billed. } \\
\text { Net indigent care costs were added (net of subsidies for such care). }\end{array}$ \\
\hline Bad debt (reported separately) & $\begin{array}{l}\text { Cost of care delivered to patients who were presumed able to pay, but from } \\
\text { whom the hospital was unable to collect. }\end{array}$ \\
\hline Unreimbursed Medicare costs (reported separately) & $\begin{array}{l}\text { Medicare contractual shortfalls that occur when hospitals are reimbursed } \\
\text { below the cost of providing services. Medicare shortfalls were added and } \\
\text { charges were adjusted by the cost-to-charge ratio. }\end{array}$ \\
\hline
\end{tabular}


After08 * Nonprofit tests the significance of the change for nonprofit hospitals relative to for-profits.

We estimate the following difference-in-difference model:

$$
\begin{aligned}
\log \left(C B_{i}\right)_{n t}= & \beta_{0}+\beta_{1}(\text { Ownership })_{n t} \\
& +\beta_{2} \text { After } 08+\beta_{3} \text { After } 08 *(\text { Nonprofit })_{n t} \\
& +\beta_{4}(\text { Hospital })_{n t}+\beta_{5}(\text { Market })_{n t}+\varepsilon_{n t}
\end{aligned}
$$

where $C B$ represents community benefits and subscript $i$ identifies the type of community benefit that hospital $n$ provides in year $t$. Community benefits were defined in Table 1. First, we estimate (1) separately for four types of community benefits: pure charity care, Medi-Cal shortfalls, bad debt and Medicare shortfalls all measured in logarithmic form to correct for normality. In addition, pure charity care and bad debt are transformed by adding the minimum of their values to correct for skewing. Finally, we estimate (1) for the new Schedule H definition of community benefits first not-including and then including unreimbursed Medicare and bad debt costs since such costs are reported to the IRS, albeit separately.

We control for hospital ownership (vector Ownership above): nonprofit, municipal and for-profit. Municipal hospital ownership includes city, county and district hospitals. For-profit ownership serves as our excluded category. Nonprofit status (variable Nonprofit) represents a corporately owned tax exempt hospital. We also control for other hospital characteristics, market characteristics, and time. Hospital characteristics (Hospital) include church affiliation, teaching status, hospital size, the presence of trauma center, and 24 hours emergency room. Hospital size is measured as the number of staffed beds. Teaching status is defined as hospitals with some residents. Hospital market characteristics reflect competitive pressures, and demand for community benefits (percent MediCal enrollment, percent uninsured, poverty rate and unemployment rate). A Herfindahl-Hirschman index (HHI) measures hospital competition; the index was constructed based on licensed bed shares. HHI is inversely related to competition, and therefore we expect it to be positively related to the supply of community dividends. We use the hospital service area (HSA) as the relevant hospital market. Unlike the market definitions based on geo-political borders (e.g., county), the HSA relies on patient flows. The 2006-2010 period of time covers a major recession in the US. County-specific unemployment rate, percent uninsured, and poverty rate capture a changing demand for hospital community benefits.

The coefficient of interest is $\beta_{3}$ : if $\beta_{3}$ is statistically significant, there is a significant change in the supply of community benefits after the IRS Form 990 Schedule H was phased in. On the other hand, if the interaction coefficient is insignificant, then IRS policy change did not significantly affect charity care supply of nonprofit hospitals.

\subsection{Data}

According to the National Health Policy Forum (2009), p. 6 :

"For the 2008 tax year (2009 filing), hospitals are only required to submit Part V (Facility Information), which requests the name and address of all facilities licensed, registered, or similarly recognized as a health care facility under state law. Filing of Parts I through IV and Part VI are optional for the 2009 filing, but hospitals will be required to submit the complete schedule for the 2009 tax year (2010 filing)."

We used tax years 2006-2007 and 2009-2010 data to assess the impact of Schedule $\mathrm{H}$ timing on community benefits by California general acute care (GAC) hospitals. Thus, we treat 2008 tax year (2009 filing) as excluded transition year.

Hospital-level data came from the Annual Hospital Disclosure Reports published by California's Office of Statewide Health Planning and Development (OSHPD). The annual reports offer a detailed description of hospital characteristics as well as costs and revenues. The analyses excluded any specialty hospitals, long-term care facilities, and Kaiser hospitals (since the Kaiser hospitals treat Kaiser members only and do not report to OSHPD). Table 2 provides descriptive statistics for all hospitals under consideration.

Descriptive statistics in Table 2 show that our sample contained $37.13 \%$ private nonprofit hospitals. Of the four community benefits, Medicare and MediCal shortfalls were the largest, on average. There is also a large variability in supply of community benefits across hospitals. Simple descriptive statistics before and after Schedule H (not shown here) reveal that hospitals that used to supply negative amounts of charity care (i.e. provided less pure charity care than subsidies received for such care) increased their supply of pure charity care. After tax year 2008, all hospitals report positive amounts of pure charity care. This result is not surprising since Schedule $\mathrm{H}$ requires hospitals to adjust for subsidies and to report all contributions at cost.

All hospitals in our sample were located in competitive markets with HHI below 1800 with mean HHI of 621.

\section{RESULTS}

Table 3 shows our difference-in-difference results for all components of community care separately. 
Table 2. Means and standard deviations.

\begin{tabular}{|c|c|c|}
\hline Variables & Overall means & Standard deviations \\
\hline \multicolumn{3}{|l|}{ Dependent Variables } \\
\hline Charity Care & 7.612 & 1.078 \\
\hline MediCal Shortfalls & 9.513 & 1.584 \\
\hline Medicare Shortfalls & 10.13 & 1.555 \\
\hline Bad Debt & 7.888 & 0.8788 \\
\hline Charity Care + Medical Shortfalls & 9.604 & 1.596 \\
\hline Charity Care + Medical Shortfalls + Medicare Shortfalls + Bad Debt & 10.77 & 1.436 \\
\hline \multicolumn{3}{|l|}{ Ownership Variables } \\
\hline Nonprofit, private & 0.3713 & 0.4833 \\
\hline Nonprofit, public & 0.0405 & 0.1971 \\
\hline Municipal & 0.2055 & 0.4042 \\
\hline \multicolumn{3}{|l|}{ Hospital Characteristics } \\
\hline Church affiliated & 0.1165 & 0.3209 \\
\hline Education & 2.535 & 0.8323 \\
\hline ER & 0.9005 & 0.2995 \\
\hline Trauma & 0.3657 & 0.8792 \\
\hline Staffed Beds & 4.838 & 0.9472 \\
\hline \multicolumn{3}{|l|}{ Area Characteristics } \\
\hline HHI & 6.251 & 0.6704 \\
\hline Percent MediCal & 2.073 & 0.9979 \\
\hline \multicolumn{3}{|l|}{ Market Variables } \\
\hline Unemployment Rate & 8.791 & 4.115 \\
\hline Poverty Ratio & 13.66 & 3.755 \\
\hline Percentage of Uninsured & 19.98 & 4.082 \\
\hline Number of hospitals & 1236 & \\
\hline
\end{tabular}

Note: All dependent variables are in logarithm. Charity care and Bad Debt are transformed by adding the minimum value. All dependent variables are scaled down by 1000 . Staffed beds, HHI and percent medical are in logarithm.

Empirical results show that community benefits provided by private nonprofit hospitals relative to for-profits did not increase after Schedule $\mathrm{H}$ was enacted. In fact, we see a significant decrease in bad debt after the policy change. This significant decrease in bad debt may be due to the fact that some types of charity care can be "involuntary" community care, from hospital's perspective. For example, although hospitals can pursue more aggressive collection practices, the amount of bad debt is sometimes difficult for hospitals to control. Table 3 also shows that nonprofit hospitals supply more pure charity care and bad debt than for-profits although supply of these community benefits did not increase after Schedule $\mathrm{H}$ was phased in. For Medicare contractual shortfalls there are no significant differences between nonprofit hospitals and for-profits in similar markets.

Table 4 summarizes the results for the two alternative community benefits definitions proposed by the IRS
Form 990.

Data from California shows that nonprofit hospitals did not provide more pure charity and MediCal shortfalls relative to for-profit hospitals (in fact they provided significantly less) and the supply of such benefits did not increase after 2008. For the broader definition that includes pure charity care, MediCal, bad debt and Medicare contractual shortfalls, the nonprofit hospitals actually supply less benefits than for-profits, and their dedication to this broader type of community benefits did not increase after 2008.

Our results are consistent with previous findings by CBO (2006) that only found significant differences in community benefits between the nonprofit hospitals and for-profit hospitals when nonprofit hospitals were required by states to dedicate a specific proportion of their income to community benefits. Right now Schedule H does not set a minimum standard of community benefits 
Table 3. Difference-in-difference regression results for pure charity care discounts, medical contractual shortfalls, bad debt, medicare contractual shortfalls.

\begin{tabular}{ccccc}
\hline Variables & Pure & Medical & Bad Debt & Medicare \\
\hline Nonprofit, private & $0.146^{* *}(0.066)$ & $-0.29^{* * *}(0.095)$ & $0.233^{* * *}(0.063)$ & $0.119(0.087)$ \\
After08 (dummy) & $0.26^{*}(0.135)$ & $0.135(0.133)$ & $0.207^{* *}(0.089)$ & $0.065(0.14)$ \\
After08 (Nonprofit) & $0.079(0.091)$ & $0.069(0.111)$ & $-0.178^{* *}(0.073)$ & $0.052(0.107)$ \\
(interactionterm) & & & $0.225^{* *}(0.097)$ & $0.102(0.102)$ \\
Nonprofit, public & $0.125(0.155)$ & $0.107(0.12)$ & $0.089(0.067)$ & $-10.08^{* * *}(0.105)$ \\
Municipal & $-0.284^{* * *}(0.095)$ & $-0.224^{* *}(0.104)$ & $0.161^{* * *}(0.061)$ & $0.186^{* *}(0.083)$ \\
Church & $0.212^{* * *}(0.071)$ & $0.043(0.093)$ & $-0.045(0.036)$ & $-0.042(0.032)$ \\
Education & $-0.093^{* *}(0.046)$ & $-0.344^{* * *}(0.036)$ & $0.506^{* * *}(0.124)$ & $-0.606^{* * *}(0.172)$ \\
ER & $0.394^{* * *}(0.07)$ & $0.910^{* * *}(0.173)$ & $0.106^{* * *}(0.021)$ & $0.048^{* *}(0.023)$ \\
Trauma center & $0.174^{* * *}(0.03)$ & $0.091^{* * *}(0.027)$ & $0.391^{* * *}(0.022)$ & $10.01^{* * *}(0.06)$ \\
Staffed beds & $0.476^{* * *}(0.028)$ & $10.075^{* * *}(0.043)$ & $0.411^{* * *}(0.072)$ & $0.225^{*}(0.127)$ \\
HHI & $0.447^{* * *}(0.105)$ & $0.13(0.128)$ & $0.196^{* * *}(0.046)$ & $0.028(0.082)$ \\
Percent Medical & $0.274^{* * *}(0.059)$ & $0.114(0.083)$ & $0.014(0.01)$ & $0.044^{* * *}(0.017)$ \\
Unemployment Rate & $0.009(0.015)$ & $0.027^{*}(0.016)$ & $-0.025^{* * *}(0.007)$ & $-0.044^{* * *}(0.011)$ \\
Poverty Rate & $-0.009(0.008)$ & $-0.016(0.012)$ & $0.009(0.007)$ & $-0.008(0.01)$ \\
Percentage of Uninsured & $-0.0003(0.011)$ & $-0.008(0.01)$ & $20.47(0.6)$ & $30.79(10.01)$ \\
Intercept & $10.64(0.965)$ & $30.03(0.98)$ & 1236 & 1232 \\
N & 1236 & 1226 & 00.36 & 00.62 \\
R-squared overall & 00.38 & 00.61 & $p$ & \\
\hline
\end{tabular}

Note: All continuous variables are in log form; robust standard errors are in parentheses. ${ }^{*} p<0.10,{ }^{* *} p<0.05,{ }^{* * *} p<0.01$.

that is expected of nonprofit hospitals.

Other significant variables included hospital characteristics: church affiliated hospitals, larger hospitals and hospitals with emergency rooms and trauma centers supplied more community benefits. Hospitals located in more concentrated markets were able to provide more community benefits in most specifications of the model. Thus, competitive pressures do decrease the amount of community benefits that hospitals are able to provide.

\section{Sensitivity Analyses}

To better capture market characteristics (such as managed care penetration), we re-estimated our model with HSA fixed effects. Controlling for fixed effects did not change the main conclusions of this paper. In addition, we repeated our analysis without 2009 year since it was a transition year for some states. Using only the latest data did not affect our conclusions.

Finally, we transformed our dependent variable and estimated a probit regression to check whether nonprofit hospitals dedicated higher proportion of their net patient revenues to community benefits after Schedule $\mathrm{H}$ was phased in. In 2007 Senate Finance Committee (2007) led by senator Charles Grassley (R-Iowa) proposed that nonprofit hospitals devote at least $5 \%$ of their net patient revenues to charity care [12]. In our data, only $5.22 \%$ of nonprofit hospitals dedicated more than $5 \%$ of their net patient revenues to pure charity care and $92.22 \%$ dedicated more than $5 \%$ of net patient revenues to pure charity care and Medicaid shortfalls after 2008. Probit results showed that implementation of Schedule $\mathrm{H}$ did not increase the percentage of net patient revenues that nonprofits allocate to charity care relative to for-profit hospitals. This result held true for alternative definitions of charity care and net patient revenue cut-offs.

\section{DISCUSSION}

The results of this study suggest that nonprofit hospitals do not supply more community benefits as defined by the IRS and they do not increase supply of community benefits in response to the mandatory reporting at the federal level.

The information requested in the newly adopted IRS Schedule H in Form 990 collects the costs of charity care, Medicaid shortfalls and, separately, Medicare shortfalls, as well as a bad debt. So far the results of this study are consistent with previous research and show that mandatory data reporting which does not set a specific minimum standard of community benefits expected of nonprofits, may not significantly change nonprofit hospital's community orientation. It is likely that supporters of a minimum standard for community benefits will use the 
Table 4. Difference-in-difference regression results for the two definitions of community benefits.

\begin{tabular}{|c|c|c|}
\hline Variables & Pure + Medical & Pure + Medical + Bad Debt + Medicare \\
\hline Nonprofit, private & $-0.239^{* *}(0.094)$ & $-0.019(0.07)$ \\
\hline After08 (dummy) & $0.161(0.132)$ & $0.173(0.118)$ \\
\hline $\begin{array}{c}\text { After08(Nonprofit) } \\
\text { (interactionterm) }\end{array}$ & $0.088(0.110)$ & $0.057(0.086)$ \\
\hline Nonprofit, public & $0.121(0.120)$ & $-0.024(0.094)$ \\
\hline Municipal & $-0.218^{* *}(0.104)$ & $-0.552^{* * *}(0.087)$ \\
\hline Church & $0.08(0.092)$ & $0.086(0.068)$ \\
\hline Education & $-0.335^{* * *}(0.035)$ & $-0.195^{* * *}(00.26)$ \\
\hline ER & $0.961^{* * *}(0.174)$ & $0.612^{* * *}(0.135)$ \\
\hline Trauma center & $0.101^{* * *}(0.026)$ & $0.078^{* * *}(0.021)$ \\
\hline Staffed beds & $1.08^{* * *}(0.044)$ & $1.05^{* * *}(0.044)$ \\
\hline HHI & $0.174(0.127)$ & $0.194^{*}(0.104)$ \\
\hline Percent Medical & $0.135(0.083)$ & $0.082(0.07)$ \\
\hline Unemployment Rate & $0.025(0.016)$ & $0.024(0.015)$ \\
\hline Poverty Rate & $0.011(0.011)$ & $-0.019^{*}(0.010)$ \\
\hline Percentage of Uninsured & $-0.005(0.01)$ & $-0.009(0.008)$ \\
\hline Intercept & $2.68(0.98)$ & $4.48(0.794)$ \\
\hline $\mathrm{N}$ & 1227 & 1236 \\
\hline R-squared overall & 0.61 & 0.69 \\
\hline
\end{tabular}

Note: All continuous variables are in log form; robust standard errors are in parentheses. ${ }^{*} p<0.10,{ }^{* *} p<0.05,{ }^{* * *} p<0.01$.

data provided in Schedule $\mathrm{H}$, and the public disclosure of such data may then put pressure on nonprofit hospitals to provide adequate amount of community benefits relative to peer institutions. In 2007 Senator Grassley proposedin a draft to the Senate Finance Subcommittee - that nonprofit hospitals devote at least $5 \%$ of their operating revenues or expenses (whichever is greater) to charity care. Although this proposal did not pass, IRS Schedule $\mathrm{H}$ makes such standard easier to implement in the future.

Finally, it is important to note that after all of the provisions of the Patient Protection and Affordable Care Act (ACA) are phased in by 2014, the role of different components of community benefits and the purpose of hospital tax exemption are going to change. The importance of pure charity care is likely to decrease and with proposed expansion of Medicaid and cuts in Medicare payments, the role of contractual shortfalls of public insurance will certainly increase. Hsieh and Bazzoli (2012) showed that community benefits are sensitive to Medicaid payment reductions [13]. Thus, we expect ACA to change the relative size and importance of different community benefits.

\section{Limitations of the Study}

This study uses a sample of California hospitals only, and thus our results may not be generalized to be translated to other states. Specifically, California already collected hospital financial data including community benefits data through OSHPD, although the data were never collected at cost. Thus, the level of scrutiny is higher for hospitals in states that collect hospital data. The impact of Schedule H may be more significant for states that do not collect community benefits data although the differences for hospitals in such states cannot be estimated.

The effect of Schedule $\mathrm{H}$ is difficult to isolate due to the effects of the recession that occurred during the 2008 and 2010 period. However, we believe that differencein-difference design does correct for the recession since all hospitals were affected by the economic downturn. For this reason we believe that variables that capture demand for indigent care (such as poverty rate, unemployment and uninsurance) were not significant.

Finally, in this study we only looked at the differences in community benefits contributions as defined by Schedule $\mathrm{H}$ by for-profit and nonprofit hospitals. To es- 
timate whether nonprofit hospitals warrant their tax exemption, one should also collect information on tax contributions by for-profit hospitals since taxes do benefit the hospital communities. This is still an area for future study.

\section{ACKNOWLEDGEMENTS}

The authors are indebted to all of the participants of the Annual Innovations in the Health care Systems Symposium of the McCombs School of Business at the University of Texas at Austin.

\section{REFERENCES}

[1] Kane, N.M. (2006) Statement to the United States Senate Committee on finance, taking the pulse of charitable care and community benefit at nonprofit hospitals, Washington DC, 13 September.

http://finance.senate.gov/imo/media/doc/091306nktest.pd f

[2] US Government Accountability Office (GAO) (2008) Variation in standards and guidance limits comparison of how hospitals meet community benefit requirement. http://www.gao.gov/assets/290/280709.pdf

[3] Salinsky, E. (2009) Schedule H: New community benefit reporting requirements for hospitals. Issue Brief National Health Policy Forum, 21, 1-25.

[4] Gray, B. and Schlesinger, M. (2009) Charitable expectations of nonprofit hospitals: Lessons from Maryland. Web Exclusive, Health Affairs, w809-w821.

[5] Hellinger, F.J. (2009) Tax-exempt hospitals and community benefits: A review of state reporting requirements. Journal of Health Politics, Policy and Law, 34, 37-61. http://dx.doi.org/10.1215/03616878-2008-991

[6] Sutton, J.P. and Stensland, J. (2004) Promoting accountability: Hospital charity care in California, Washington State, and Texas. Journal of Health Care for the Poor and Underserved, 15, 237-250. http://dx.doi.org/10.1353/hpu.2004.0030

[7] US Congressional Budget Office (CBO) (2006) Nonprofit hospitals and the provision of community benefits. CBO, Washington DC.

[8] Morrisey, M.A., Wedig, G.J. and Hassan, M. (1996) Do nonprofit hospitals pay their way? Health Affairs, 15, 132-144. http://dx.doi.org/10.1377/hlthaff.15.4.132

[9] Norton, E.C. and Staiger, D.O. (1994) How hospital ownership affects access to care for the uninsured. RAND Journal of Economics, 25, 171-185. http://dx.doi.org/10.2307/2555860

[10] Schneider, H. (2007) Paying their way? Do nonprofit hospitals justify their favorable tax treatment? Inquiry, 44, 187-199. http://dx.doi.org/10.5034/inquiryjirnl_44.2.187

[11] Bazzoli, G.J., Clement, J.P. and Hsieh, H. (2010) Community benefit activities of private, nonprofit hospitals. Journal of Health Politics, Policy and Law, 36, 999-1026. http://dx.doi.org/10.1215/03616878-2010-036

[12] Senate Finance Committee (2007) Tax-exempt hospitals: Discussion draft. http://grassley.senate.gov/public/releases/2007/07182007. pdf

[13] Hsieh, H. and Bazzoli, G.J. (2012) Medicaid disproportionate share hospital payment: How does it impact hospitals' provision of uncompensated care? Inquiry, 49, 254-267. http://dx.doi.org/10.5034/inquiryjirnl 49.03.02

HAS - Hospital Service Area

IRS-Internal Revenue Service

OSHPD_Office of Statewide Health Planning and Development

SCHIP_State Children's Health Insurance Program 